\title{
Os senadores do Paraná no contexto da Revolução de 1930: capitais políticos e familiares
}

Natália Cristina Granato 1

\begin{abstract}
RESUMO: O presente trabalho procura trabalho procura discutir quais são os capitais políticos e familiares dos senadores do Paraná da legislatura anterior à Revolução de 1930 (que assumiram o mandato a partir de 1928) e posterior ao mesmo acontecimento histórico (eleitos em 1933). Entendemos tal conjuntura como um processo de "modernização conservadora". Ao analisar os cinco senadores desta delimitação temporal, a saber: Carlos Cavalcanti de Albuquerque, Marins Alves de Camargo, Caetano Munhoz da Rocha (estes pertencentes à legislatura anterior ao movimento de 1930), Antônio Jorge Machado Lima e Flávio Carvalho Guimarães, (eleitos no período pós-1930), pretendemos identificar quais sãos os atributos sociais, políticos e familiares de suas trajetórias, averiguando quais foram os impactos que a Revolução de 1930 provocaram nas suas carreiras. Tendo como referência algumas indagações de Pierre Bourdieu a respeito dos acúmulos de capitais pelos agentes sociais, refletiremos sobre as mudanças e permanências que a representação do Paraná no Senado presenciou com a Revolução de 1930.
\end{abstract}

Palavras-chave: Revolução de 1930; Paraná; agentes políticos.

\section{The senators of Paraná in the context of the Revolution of 1930: political and family capitals}

\begin{abstract}
The present paper seeks work to discuss the political and family capitals of the senators of Paraná of the legislature prior to the 1930 Revolution (who took office after 1928) and after the same historical event (elected in 1933). We understand this situation as a process of "conservative modernization". When analyzing the five senators of this temporal delimitation, Carlos Cavalcanti de Albuquerque, Marins Alves de Camargo, Caetano Munhoz da Rocha (who belonged to the legislature prior to the 1930 movement), Antônio Jorge Machado Lima and Flávio Carvalho Guimarães, Post-1930 period), we intend to identify the social, political and family attributes of their trajectories, ascertaining the impact of the 1930 Revolution on their careers. Based on Pierre Bourdieu's inquiries about the accumulation of capital by social agents, we will reflect on the changes and permanences that the Parana representation in the Senate witnessed with the 1930 Revolution.
\end{abstract}

Keywords: Revolution of 1930; Paraná; Agents.

- Enviado em 01/05/2017

- Aprovado em 17/05/2017

1 Doutoranda em Sociologia pela Universidade Federal do Paraná, sob orientação do Prof. Dr. Ricardo Costa de
Oliveira, na linha de pesquisa Cidadania e Estado. Mestra em Sociologia, Bacharela e Licenciada em Ciências Sociais
pela mesma instituição. Professora de Sociologia do Quadro Próprio do Magistério do Paraná. Uma versão preliminar
desse texto foi apresentada no VIII Seminário Nacional de Sociologia e Política realizado de 17 a 19 de maio de 2017
na UFPR. E-mail: nataliagranato@hotmail.com 


\section{INTRODUÇÃO}

A república no Brasil é marcada por momentos de instabilidades e golpes na política. A mesma nasceu a partir de um golpe militar em 1889, inaugurando a fase que ficou conhecida pela historiografia como "República Velha", na qual estavam presentes inúmeros vícios políticos, econômicos e sociais que desencadearam em uma revolta entre oligarcas dissidentes, juntamente com outros setores insatisfeitos. Tal inflexão culminou na Revolução de 1930, outro golpe militar com apoio de forças política e sociais civis, que inaugurou um novo período na política brasileira, que perdurou até 1945 , início de uma nova fase de instabilidade política².

O período da Primeira República é caracterizado por muitos vícios, como o sistema oligárquico no qual apenas alguns grupos políticos comandavam os estados fazendo dos seus interesses hegemônicos frente aos demais, a corrupção eleitoral, a baixa participação de setores emergentes da população como o operariado, as classes médias urbanas, a burguesia industrial, entre outras. O país tinha a maioria da população vivendo no campo, sob péssimas condições de vida e sem direitos sociais, enquanto o poder político e econômico era concentrado e distribuído entre os grandes proprietários rurais, oligarcas e coronéis. Tal cenário gerou insatisfações de oligarquias dissidentes, classes urbanas e inúmeros movimentos contestatórios que eclodiram especialmente na década de 1920. É neste cenário que a Revolução de 1930 ocorre, sob a liderança de Getúlio Vargas, candidato da Aliança Liberal para a presidência derrotado nas eleições de 1930, com o apoio de setores militares, oligarcas dissidentes, dentre outros grupos sociais dissidentes. A reflexão sobre o termo "revolução" torna-se importante para uma análise do período. Boa parte da literatura sobre a Revolução de 1930 no Brasil caracteriza este evento como um processo como "modernização conservadora". Boris Fausto (1997, p.116) salienta que tal processo não modificou as relações de produção baseadas no grande latifúndio, e "o colapso da hegemonia burguesa do café não conduz ao poder político de outra classe ou fração de classe com exclusividade". Com uma interpretação parecida, José Carlos Pereira (1984), defende que a

\footnotetext{
${ }^{2}$ Tal fase propiciou grandes transformações sociais e econômicas para o Brasil até 1964, ano de outro golpe, que inaugurou uma ditadura militar, esta finalizada na década de 1980. Desde então, o Brasil presenciou a redemocratização e desde 2016 vivencia uma nova crise política e econômica, geradora de grandes instabilidades e rupturas institucionais, especialmente em relação ao papel do Estado e sua ação promotora de desenvolvimento, especialmente nos setores sociais e nas políticas sociais direcionadas às classes populares.
} 
Revolução de 1930 não tinha em sua origem um conteúdo industrialista, nem constituiu um movimento liderado pela burguesia industrial ascendente contra o agrarismo predominante na Primeira República. A Revolução de 1930 buscou a incorporação das aspirações das classes em ascensão (burguesia industrial, operariado urbano) nas pautas do Estado (ou seja, quebrou o monopólio exclusivo das oligarquias rurais sobre o Estado). Mas isso não significa que tais classes hegemônicas da República Velha foram excluídas do processo político que estavam em reformulação. Gláucio Ary Dillon Soares $(1973$, p.36) é outro autor que salienta conservação da infraestrutura econômica vigente e a modificação do sistema político promovidos pela Revolução de 1930. Luciano Martins (1980, p.673) caracteriza a Revolução de 1930 como uma "crise da oligarquia", pois se a estrutura agrária não foi modificada, logo as bases sociais do coronelismo foram mantidas, bem como a hegemonia do voto rural. Tal processo resultou na modernização da manipulação eleitoral e do patrimonialismo e também proporcionou a inclusão de atores emergentes na cena política, algo que "o sistema representativo da confederação oligárquica fora incapaz de resolver" (MARTINS, 1980. p.680). Outra autora que compartilha deste ponto de vista é Maria do Carmo Campello de Souza, salientando que os interesses econômicos dominantes do período anterior não foram marginalizados. Segundo a autora, a Revolução de 1930 redefiniu os "canais de acesso e influência para a articulação de todos os interesses, velhos ou novos, com o poder central" (SOUZA, 1976, p.85).

O cenário nacional acima reportado remete aos estados da federação e a uma reflexão sobre o caráter continuísta ou transformador que a Revolução de 1930 propiciou ao Paraná. Um importante texto sobre a Era Vargas no Paraná intitula-se "Notas sobre a política paranaense no período de 1930 a 1945", de Ricardo Costa de Oliveira. O autor enfatiza o decisivo apoio do Paraná às tropas rebeldes que derrubaram Washington Luís e a participação dos militares chefiados por Plínio Tourinho para o sucesso da empreitada. Analisando o perfil das autoridades nomeadas pela interventoria do irmão de Plínio Tourinho, Mário Tourinho, o autor destaca a "continuidade de tradicionais grupos e famílias no poder" (OLIVEIRA, 2004, p.18), a começar pelo próprio interventor, membro de uma tradicional família local. Esta dinâmica continuou com o longo período de interventoria de Manoel Ribas, da qual o autor apontou a presença de membros de tradicionais famílias nas secretarias de estado, na Associação Comercial do Paraná, na Federação das Indústrias do Paraná, entre os deputados eleitos para a Assembleia Nacional Constituinte em 1933 e os deputados federais eleitos em 1934 e os deputados estaduais eleitos em 1935. Oliveira 
destaca também que durante o governo Manoel Ribas, "vários políticos que trabalhavam no regime deposto pela Revolução de 1930 voltaram a cargos de poder" (OLIVEIRA, 2004, p.25).

Tendo tais considerações em vista, o presente trabalho procura discutir quais são os capitais políticos e familiares dos senadores do Paraná da legislatura anterior à Revolução de 1930 (que assumiram o mandato a partir de 1928) e posterior ao mesmo acontecimento histórico (eleitos indiretamente pelos deputados federais paranaenses para assumirem em 1935). Analisando a trajetória de cinco senadores desta conjuntura, pretendemos identificar quais sãos os atributos sociais, políticos e familiares de suas trajetórias, averiguando quais foram os impactos que a Revolução de 1930 provocaram nas suas carreiras. Tendo como referência algumas indagações de Pierre Bourdieu a respeito dos acúmulos de capitais pelos agentes sociais, refletiremos sobre as mudanças e permanências que a representação do Paraná no Senado presenciou com a Revolução de 1930.

A relação entre os atores e a estrutura social é um dos principais temas da Sociologia. Um teórico que ajuda nesta reflexão no presente projeto é Pierre Bourdieu. Tentando superar a dicotomia entre o subjetivismo, incapaz de "dar conta da necessidade do mundo social" e o objetivismo, que toma as realidades construídas "fora da história do indivíduo e do grupo" (BOURDIEU, 2009, p.86), Bourdieu concentra suas atenções no conceito de habitus, que procura articular o ator e a estrutura social, o homem e a história (ORTIZ, 1983). O autor argumenta que o habitus corresponde ao mundo social incorporado pelos indivíduos através da socialização, tornando as práticas e representações dos indivíduos que compartilham habitus parecidos regradas e regulares. Segundo Bourdieu (2004, p.158-159), o habitus varia segundo a posição que os agentes ocupam em determinado espaço do mundo social. Os espaços sociais são denominados por Bourdieu de campos. Cada campo possui diferentes espécies de capital, como o econômico, o político, o cultural, o social, o simbólico, entre outros. Os campos possuem relativa autonomia entre eles, articulando-os entre si. Para cada senador analisado, pretendemos destacar quais eram seus capitais políticos (cargos ocupados nos poderes executivo, legislativo e judiciário), sociais (famílias aos quais pertenciam e conexões estabelecidas), culturais (formação, participação em instituições que fazem parte da intelectualidade paranaense) e econômicos (ocupação e propriedades). Tal análise será feita nas seções seguintes deste trabalho. 


\section{SENADORES DO PARANÁ DO PERÍODO PRÉ-REVOLUÇÃO DE 1930}

O primeiro dos três senadores da conjuntura da Revolução de 1930 analisados é Carlos Cavalcanti de Albuquerque. Nascido no Rio de Janeiro em 1864, é filho de Inocêncio José Cavalcanti de Albuquerque, militar, combatente e morto na Guerra do Paraguai e Joaquina da Mota Cavalcanti de Albuquerque (CASA $\mathrm{CIVIL}^{3}$ ). Sua família possuía tradição militar, sendo sobrinho do General José de Almeida Barreto, que participou da Revolução Praieira, ocorrida em Pernambuco, em 1848, além de combater na Guerra do Paraguai, ao lado de seu irmão, de 1866 a 1868. Foi participante ativo da Proclamação da República, em 1889, eleito senador pela Paraíba, em 1890, aliado de Deodoro da Fonseca, opositor de Floriano Peixoto. Membro do Partido Autonomista, na Paraíba, e do Partido Democrata, na capital federal, também foi Ministro do Supremo Tribunal Militar (DHBB CPDOC FGV4).

Seguindo o habitus familiar, Carlos Cavalcanti de Albuquerque formou-se na Escola de Cadetes de Porto Alegre em 1879. Exerceu os cargos de Chefe do Estado-Maior da 1a Região Militar e comandante do 10 Regimento de Infantaria da Vila Militar.

Residindo no Paraná, casou-se com Francisca Munhoz da Rocha, irmã de Caetano Munhoz da Rocha. Tal união matrimonial foi decisiva para a consolidação de sua carreira política no estado, somando com os capitais políticos, econômicos e culturais herdados de sua própria família, estabelecida no Paraná desde meados do século XIX, detentora do título genealógico Carrasco dos Reis (OLIVEIRA, 2000, p.387). Seu casamento proporcionou-lhe a integração à uma das famílias tradicionais mais influentes e antigas do Paraná, que dividia com a família Camargo a hegemonia política durante o período anterior à Revolução de 1930. Ocupou os cargos de Deputado Federal pelo Paraná, de 1900 a 1905 e de 1909 a 1911, Presidente do Paraná, pelo Partido Republicano, de 1912 a 1916 (venceu oposições internas ao seu vice, Affonso Camargo, lideradas por Alencar Guimarães e Generoso Marques dos Santos, seu governo foi atravessado pela Guerra do Contestado) e Senador pelo Paraná, de 1921 a 1930. (GOULART, 2008, p.132; NICOLAS S/D; OLIVEIRA, 2000, p.387-388).

\footnotetext{
3 Carlos Cavalcanti de Albuquerque. Disponível el http://www.casacivil.pr.gov.br/modules/conteudo/conteudo.php?conteudo=46. Acesso 13.maio.2017.

${ }^{4}$ CPDOC FGV. Verbete ALMEIDA BARRETO. Disponível em: http://cpdoc.fgv.br/sites/default/files/verbetes/primeirarepublica/BARRETO,\%20Almeida.pdf. . Acesso 13.maio.2017.
} 
Cavalcanti de Albuquerque ocupou cargos políticos de destaque por três décadas, de 1900 a 1930 (CASA CIVIL ; DHBB CPDOC FGV6). Sua família associou-se às principais famílias políticas do Paraná, que revezavam a presidência do estado por quase duas décadas (Carlos Cavalcanti de Albuquerque, casado com uma Munhoz da Rocha, ocupou-a de 1912 a 1916, tendo como vice Afonso Camargo, Eudoro Cavalcanti de Albuquerque, desembargador do Tribunal de Justiça do Paraná, casado com Amasília Camargo, irmã de Afonso Camargo, presidente do Paraná de 1916 a 1920 e de 1928 a 1930 e Caetano Munhoz da Rocha, presidente do Paraná de 1920 a 1928) (OLIVEIRA, 2000, p.387) Estas famílias foram alvos da Revolução de 1930. Afonso Camargo foi destituído do cargo de presidente do Paraná em 1930. Eudoro Cavalcanti de Albuquerque, familiar de Carlos Cavalcanti de Albuquerque e cunhado de Afonso Camargo foi exonerado do cargo de desembargador do Tribunal de Justiça (TJ PARANÁ ${ }^{7}$. Caetano Munhoz da Rocha teve seu mandato de senador cassado pelos acontecimentos revolucionários. Depois de um curto período de tempo, porém, Eudoro Cavalcanti de Albuquerque recuperou seu cargo de desembargador e Caetano Munhoz da Rocha retomou à vida política. Outros políticos, como Afonso Camargo e Carlos Cavalcanti de Albuquerque não retomaram as suas carreiras políticas. Fora dos círculos de poder, Cavalcanti de Albuquerque incrementava seus capitais intelectuais, sendo professor catedrático de Economia Política da Faculdade de Engenharia do Paraná.

Outro senador do período pré-revolucionário é Marins Alves de Camargo, pertencente à família Camargo, um dos principais alvos da Revolução de 1930 na sua primeira fase. Nascido em Guarapuava, no ano de 1882, era filho de Pedro Alves da Rocha Loures e de Francisca de Paula Camargo Loures. Pertence a uma família estabelecida no Paraná desde meados do século XIX, detentora dos títulos genealógicos Carrasco dos Reis e Moreira da Rocha (OLIVEIRA, 2000, p.387). Camargo é descendente de Antônio de Sá Camargo (Visconde de Guarapuava) e do Padre José Antônio de Camargo Araújo, deputado provincial (OLIVEIRA, 2000, p.387).

\footnotetext{
5 Carlos Cavalcanti de Albuquerque. Disponível http://www.casacivil.pr.gov.br/modules/conteudo/conteudo.php?conteudo=46. . Acesso 13.maio.2017.

6 Carlos Cavalcanti de Albuquerque. Disponível em: http://cpdoc.fgv.br/sites/default/files/verbetes/primeirarepublica/ALBUQUERQUE,\%20Carlos\%20Cavalcanti\%20de.pdf. . Acesso 13.maio.2017.
}

7 Eudoro Cavalcanti de Albuquerque. Disponível em: https://www.tjpr.jus.br/desembargadores-tipr-museu//asset publisher/V8xr/content/des-eudoro-cavalcanti-de-albuquerque/397262?inheritRedirect=false. . Acesso 13.maio.2017. 
Casou-se com Etelvina Pinto Rebelo de Camargo, também pertencente à classe dominante tradicional paranaense (OLIVEIRA, 2000, p.387). Formou-se em Ciências Jurídicas e Sociais pela Faculdade de Direito de São Paulo em 1903. Membro e presidente do Instituto Histórico e Geográfico do Paraná, co-fundador e diretor do Ginásio Curitibano, Marins Camargo também exerceu os cargos de Promotor Público de Curitiba (1904-1905) e Professor da Universidade do Paraná da cátedra de Direito Internacional Público da Faculdade de Direito, acumulando além de capitais políticos, familiares e econômicos, os capitais culturais e acadêmicos (CASA CIVIL ${ }^{8}$; DHBB (PDOC FGV ${ }^{9}$ ).

O familiar mais influente de Marins Camargo na política é o seu irmão Afonso Alves de Camargo, vice-presidente do Paraná, de 1912 a 1916, presidente do Paraná de 1916 a 1920 e de 1928 a 1930, deputado federal de 1921 a 1922 e senador de 1922 a 1927. Também podemos citar a influência de sua irmã, Flora Camargo, casada com Bento Munhoz da Rocha Netto, governador do Paraná de 1951 a 1954.

Sendo membro de uma das famílias mais importantes da política paranaense no período pré-1930, Marins Camargo ocupou diversos cargos: foi Secretário de Estado dos Negócios do Interior, Justiça e Instrução Pública em 1912 (Governo Carlos Cavalcanti de Albuquerque); Secretário de Estado dos Negócios de Obras Públicas e Colonização em 1913 (Governo Carlos Cavalcanti de Albuquerque). Secretário Geral do Estado, 1920-1922 (Governo Caetano Munhoz da Rocha) (GOULART, 2008, p.540). Influente quadro do Partido Republicano, exercendo a sua presidência, foi também deputado estadual, sendo presidente da Assembleia Legislativa em 1920 (GOULART, 2008, p.523). Marins Camargo também foi vice-presidente do Paraná durante a segunda gestão de Caetano Munhoz da Rocha (1924-1928) e senador pelo Paraná de 1928 a 1930. Cassado pela Revolução de 1930, Marins Camargo não retomou a sua careira política em cargos eletivos (embora tenha presidido a seção regional do Partido Republicano no período pós-1945), assim como o seu irmão, Afonso Camargo. Apenas a geração posterior aos mesmos retomou parte da influência que exerciam na República Velha, com menor potência. Seu sobrinho Paulo Afonso Alves de Camargo (filho de Afonso Camargo) foi deputado estadual por sete legislaturas

8 Marins Alves de Camargo. Disponível em: http://www.casacivil.pr.gov.br/modules/conteudo/conteudo.php?conteudo=104. . Acesso 13.maio.2017.

9 Marins Camargo. Disponível em: http://cpdoc.fgv.br/sites/default/files/verbetes/primeirarepublica/CAMARGO,\%20Marins.pdf. . Acesso 13.maio.2017. 
consecutivas, iniciando em 1955, pelo Partido Republicano e finalizando em 1982, pela Aliança Renovadora Nacional. Outro sobrinho seu foi Mário Afonso Alves de Camargo (filho de Afonso Camargo), vereador em Curitiba eleito pelo Partido Republicano em 1951, tornando-se presidente da Câmara Municipal em 1953. Seu sobrinho-neto foi Affonso Camargo Neto, cujo cargo mais elevado foi o Ministério dos Transportes no governo José Sarney ${ }^{10}$.

O terceiro senador paranaense do período pré-1930 é Caetano Munhoz da Rocha. Nascido em Antonina no ano de 1879, é filho de Bento Munhoz da Rocha e Maria Leocádia Munhoz Carneiro. Membro de uma família estabelecida no Paraná desde meados do século XVIII, quando o espanhol Bento Antônio Munhoz e sua esposa Michielina Assumpção passaram a residir no Paraná (OLIVEIRA, 2000, p.392). Desde então, o acúmulo de capitais políticos, econômicos e culturais teve ascensão progressiva. Através do casamento entre Florêncio José Munhoz (filho de Bento Antônio Munhoz) com Luizia Licia de Lima (descendente de Mateus Leme e Baltazar Carrasco dos Reis), a família se torna integrante dos herdeiros dos primeiros povoadores de Curitiba, sedo detentora do título genealógico Carrasco dos Reis (OLIVEIRA, 2000, p.392).

Ao longo de sua trajetória, Caetano Munhoz casou-se por três vezes. Sua primeira esposa foi Olga de Souza. Contraiu sua segunda núpcia com Domitila Almeida, filha do Coronel Alfredo Xavier de Almeida e Maria Lúcia Grein de Almeida (GOULART, 2008, p.197). Casou-se pela terceira vez com com Sílvia Lacerda Braga, filha do Coronel Antonio da Cunha Braga e Vitória de Lacerda Braga (GOULART, 2008, p.197).

Teve, ao todo, 21 filhos, um deles foi Bento Munhoz da Rocha Neto (casado com Flora Camargo Munhoz da Rocha, filha de Afonso Camargo, aliado de Caetano Munhoz da Rocha, conforme o visto anteriormente), deputado federal constituinte em 1946, governador do Paraná, pelo Partido Republicano, de 1951 e 1955, ministro da Agricultura, governo Café Filho, 1955, e deputado federal de 1959 a 1962, pelo Partido Republicano.

Possui outros familiares influentes no campo político paranaense. Sua irmã, Francisca Munhoz da Rocha, casou-se com Carlos Cavalcanti de Albuquerque, ex-presidente do Paraná e senador (OLIVEIRA, 2000, p.392).

\footnotetext{
10 Afonso Camargo Neto também foi Presidente do Diretório Regional do PDC; Diretor, Departamento de Águas e Energia Elétrica do Paraná, 1961; Presidente Fundador, CODEPAR, 1962; Secretário do Interior e Justiça do Estado do Paraná, 1963; Secretário de Finanças, 1974, Presidente do Banco do Estado do Paraná; Secretário da Fazenda do Estado do Paraná, 1974; Vice-Governador do Paraná, 1964-1965, PDC; Senador, 1979-1987, ARENA; Senador (Constituinte), 1987-1995, PMDB; Deputado Federal, 1995-1999, PPB. Federal, 1999-2003, PFL. Deputado Federal, 2003-2007, PR, PSDB; Deputado Federal, 2007-2011, PSDB. (GRANATO, 2016)
} 
Outro parente importante é José Munhoz de Mello, que iniciou sua carreira política na geração posterior à sua, especialmente no período pós-1946. Foi deputado federal constituinte de 1946 (OLIVEIRA, 2000, p.392), promotor público nas décadas de 1930 e 1940, desembargador do TJ ${ }^{11}$, nomeado em 1948, onde também foi presidente de 1953 a 1958. Prefeito de Londrina pelo PSD, também dá nome a um município no Noroeste do Paraná ${ }^{2}$. Possuidor de capitais acadêmicos de notoriedade, foi professor e diretor da Faculdade de Direito na Universidade Federal do Paraná.

Outro parente influente cuja geração é posterior à sua é Laertes de Macedo Munhoz, deputado estadual (OLIVEIRA, 2000, p.393) pela UDN por duas legislaturas (1947-1950/19511955), eleito também em 1935. Pela linhagem Macedo, este também herdou densos capitais políticos desta família estabelecida no Paraná desde meados do século XVIII (OLIVEIRA, 2000, p.390-391). Foi presidente da ALEP entre 1953 e 1954, Secretário do Interior e Justiça do Governo Bento Munhoz da Rocha Neto, Procurador-Geral de Justiça do Estado no Governo de Adolpho de Oliveira Franco, presidente da seção paranaense da Ordem dos Advogados do Brasil, membro da Academia Paranaense de Letras, na cadeira 31, cujo patrono é seu pai, Alcides de Macedo Munhoz. Possuía grande acúmulo de capitais acadêmicos, sendo professor de Direito Penal na Universidade Federal do Paraná, onde foi vice-reitor de 1964 a 1967, promotor público, advogado geral do Estado.

Em 1953, três Munhoz ocupavam os poderes Executivo, Legislativo e Judiciário do Paraná (OLIVEIRA, 2000, p.392): respectivamente: Bento Munhoz da Rocha Netto, Laertes Munhoz da Rocha e José Munhoz de Mello. Isso revela que a geração de Caetano Munhoz da Rocha transferiu muitos capitais políticos, sociais e culturais para a geração posterior à sua. Tendo isso em mente, os parágrafos posteriores se dedicarão à exposição da trajetória de Caetano Munhoz.

Caetano Munhoz da Rocha formou-se em Medicina, na Faculdade Nacional de Medicina, localizada no Rio de Janeiro, em 1902. Atuou como Médico na Santa Casa de Misericórdia e Inspetoria de Saúde dos Portos e Ervateiro. Sua família foi responsável pela introdução da tecnologia do vapor na indústria do mate (OLIVEIRA, 2000, p.392). Acumulou capitais culturais

11 TJ PARANÁ. Disponível em: https://www.tjpr.jus.br/desembargadores-tipr-museu/Lasset publisher/V8xr/content/des-jose-munhoz-de-mello/397262?inheritRedirect=false. . Acesso 13.maio.2017.

12 PREFEITURA DE DENHOZ MELLO. Disponível http://www.munhozdemello.pr.gov.br/index.php?sessao=b054603368ncb0\&id=1267. . Acesso 13.maio.2017. 
notáveis, pertencendo ao Círculo dos Estudos Bandeirantes e ao Instituto Histórico e Geográfico Paranaense, sendo presidente deste em 1919 (CASA CIVIL ${ }^{13}$ ).

Ocupou diversos cargos ao longo de sua carreira política. Foi Deputado Estadual, Partido Republicano, de 1904 a 1917. Prefeito de Paranaguá, Paraná, 1908-1912; 1912-1915. Vicepresidente do Paraná, 1916-1920 (Governo Affonso Camargo), Secretário da Fazenda, Agricultura e Obras Públicas (Governo Affonso Camargo), Presidente do Paraná, 1920-1928, Senador, 19281930. Afastado pela Revolução de 1930, eleito deputado estadual pela União Republicana Paranaense (reunião de políticos do período anterior à 1930), cassado em 1937 (CASA CIVIL, GOULART, 2008, OLIVEIRA, 2000, DHBB- CPDOC FGV ${ }^{14}$ ).

Retomou à carreira política em pouco tempo, quando foi convidado a exercer a presidência do Departamento Administrativo do Estado de 1939 a 1940 (DAGOSTIM, 2011, p.158), durante o Estado Novo.

\section{SENADORES DO PARANÁ PÓS-REVOLUÇÃO DE 1930}

O primeiro dos dois senadores paranaenses do período pós-1930 analisados é Antônio Jorge Machado Lima. Nascido em Ponta Grossa, no ano de 1886, é um dos filhos do casal Vicente Machado da Silva Lima e Maria Antônia Machado Lima. Seu pai foi Deputado Provincial (de 1886 a 1889), Deputado Estadual (de 1891 a 1892, de 1896 a 1903) Senador pelo Paraná (1895-1902) e presidente do Paraná (1893-1894 e 1904-1907), um dos mais notáveis políticos do período pré1930 (GOULART, 2008; OLIVEIRA, 2000; ALEP ${ }^{15}$; CASA CIVIL ${ }^{16}$ ). Membro de uma família estabelecida no Paraná desde meados do século XVIII, sendo descendente de Mateus Leme

\footnotetext{
13 Caetano Munhoz da Rocha. Disponível http://www.casacivil.pr.gov.br/modules/conteudo/conteudo.php?conteudo=60. . Acesso 13.maio.2017.

14 Verbete Caetano Munhoz da Rocha. Disponível em: http://cpdoc.fgv.br/sites/default/files/verbetes/primeirarepublica/ROCHA,\%20Caetano\%20Munhoz\%20da.pdf. . Acesso 13.maio.2017.
}

${ }^{15}$ Disponível em http://www.alep.pr.gov.br/deputados. . Acesso 13.maio.2017.

16 Vicente Machado da Lilva Disponível ema http://www.casacivil.pr.gov.br/modules/conteudo/conteudo.php?conteudo=36. . Acesso 13.maio.2017. 
(CORRÊlA, 2004, p.244), um dos povoadores de Curitiba e possuidora do título genealógico Carrasco dos Reis (OLIVEIRA, 2000, p.391).

Antônio Machado era casado com Zaira Abreu Machado, filha do senador Cândido Ferreira de Abreu. A irmã de Machado era casada com um filho de Carlos Cavalcanti (GOULART, 2008, p.128). Um irmão de Antônio Machado com grande influência na política é Caio Graccho Machado Lima, deputado estadual, de 1908 a 1909 e de 1930 a 1931. Foi um dos fundadores do PSD na década de 1930 (DAGOSTIM, 2011; GOULART, 2008). Fez parte do Conselheiro do Departamento Administrativo do Estado do Paraná de 1940 a 1941, e de 1946 a 1947, sendo membro do Círculo de Estudos Bandeirantes e do Instituto Histórico e Geográfico do Paraná (DAGOSTIM, 2011, p.159). Um primo influente dos dois irmãos foi Ranulfo Pinheiro Lima, deputado federal em São Paulo, eleito no ano de 1935 (ALVES, 2003, p.229).

Esta geração de irmãos e primos herdou capitais político das gerações anteriores, especialmente àquela inserida na política da República Velha. Um dos tios dos irmãos Antônio e Caio foi José Machado Pinheiro Lima, desembargador do Tribunal de Justiça de São Paulo (OLIVEIRA, 2000, p.391) e presidente desta mesma instituição em 1903, sendo este o pai do já citado Ranulfo Pinheiro Lima. Outro tio influente é Benigno Augusto Pinheiro Lima, coronel, deputado estadual de 1906 a 1907 e chefe político em Antonina (CORRÊIA, 2006, p.245; ALEP).

Antônio Machado da Silva Lima formou-se em Direito, pela Faculdade de Direito de São Paulo, no ano de 1907. Desempenhou o cargo de promotor público em Palmeiras e Antonina entre 1908 e 1909 e procurador fiscal e consultor jurídico da Fazenda Nacional na Delegacia Fiscal do Paraná, de 1909 a 1930. Fundou e dirigiu o jornal A Tarde, em 1928, opositor dos governos estadual e federal e amplo divulgador da Aliança Liberal no Paraná. Também detinha capitais culturais, sendo membro do Instituto Histórico e Geográfico do Paraná.

A rebeldia em relação às oligarquias dominantes do estado na trajetória de Antônio Machado é de longa data. Participou da dissidência liderada pelo senador Alencar Guimarães, exercendo oposição aos políticos dominantes, a partir do ano de 1914. Machado foi um dos líderes civis da Aliança Liberal, assumindo a secretaria geral e a presidência do diretório revolucionário no estado. No período pós-1930, ocupou a Diretoria geral do Ensino no Paraná, na interventoria do general Mário Tourinho (1930-1932) e integrou o Conselho Consultivo do estado, na interventoria de Manuel Ribas (1932-1935). Fundador do PSD, em 1933, eleito deputado federal constituinte no mesmo ano. Os deputados federais do Paraná que faziam parte da 
Assembleia Nacional Constituinte de 1934 escolheram o seu nome para ocupar o cargo de Senador a partir de 1935 (DHBB CPDOC FGV ${ }^{17}$ ). Fundador do Partido Social Nacionalista do Paraná, foi apoiador da candidatura de José Américo de Almeida (candidato de Vargas) à presidência da República na eleição que se realizaria em 1938, impossibilitada pelo golpe do Estado Novo, ocorrido em 1937, que suspendeu mandatos, eleições e atividades legislativas (DHBB CPDOC FGV). Durante o Estado Novo, ocupou os cargos de Procurador do Departamento de Finanças Públicas, em 1939 e Auditor do Tribunal de Contas da União, desde a década de 1940 (DHBB CPDOC FGV).

O segundo senador paranaense do período pós-1930 é Flávio Carvalho Guimarães. Nascido em Ponta Grossa, no ano de 1891, é filho de Flávio Teodoro Carneiro Guimarães e Balbina Carvalho Guimarães, sendo membro de uma família estabelecida no Paraná desde meados do século XVIII, detentora dos títulos genealógicos Cardoso de Lima e Rodrigues de França (OLIVEIRA, 2000, p.390). Seu pai foi Prefeito de Ponta Grossa ${ }^{18}$, no ano de 1895.

Flávio Guimarães casou-se com Anita Miró Guimarães, filha de José Miró (OLIVEIRA, 1997, p. 54), coronel da região do município de Palmeira. O casal teve filhos influentes, tais como José Theodoro Miró Guimarães, Engenheiro Civil, Secretário de Agricultura de 1966 a 1967 e Secretário de Viação e Obras Públicas do Paraná, no governo Paulo Pimentel. Ministro do Tribunal de Contas do Paraná, a partir de $1969^{19}$. Outro destacado filho do casal é Plauto Miró Guimarães, prefeito de Ponta Grossa, Secretário do Interior e Justiça, durante o governo interino de Algacyr Guimarães. Plauto Guimarães casou-se com Leoni Slavieiro (GOULART, 2016), integrante de uma destacada família empresarial no Paraná. Outra filha influente de Flávio Guimarães é Eunice Guimarães Cordeiro, fundadora do Rotary Club Ponta Grossa ${ }^{20}$.

A geração dos netos de Flávio Guimarães também é influente na política paranaense contemporânea, o que demonstra a transmissão de partes consideráveis de capitais políticos e sociais. Seu neto, Plauto Miró Guimarães Filho, é Deputado Estadual, eleito consecutivamente nas

17 DHBB CPDOC FGV. Verbete Antônio Jorge Machado Lima. Disponível em: http://www.fgv.br/cpdoc/acervo/dicionarios/verbete-biografico/lima-antonio-jorge-machado. . Acesso 13.maio.2017.

18 Prefeitos de Ponta Grossa. Disponível em: http://www.plantaodacidade.com.br/novo/prefeitos. . Acesso 13.maio.2017.

19 DICIONÁRIO HISTÓRICO E GEOGRÁFICO DOS CAMPOS GERAIS. Disponível em: http://www.uepg.br/dicion/verbetes/a-m/guimaraes jose.htm. . Acesso 13.maio.2017.

20 Biografia: Eunice Miró Guimarães Cordeiro . Disponível em: http://sme.pontagrossa.pr.gov.br/anfiteatro.php. . Acesso 13.maio.2017. 
eleições de 1994, 1998, 2002, 2006, 2010, 2014, desempenhando papeis de destaque dentro da Assembleia Legislativa e exercendo grande influência nos círculos de poder na região de Ponta Grossa $\left(\right.$ ALEP $\left.^{21}\right)$.

A família do senador Flávio Guimarães possui outras figuras influentes, como Alô Ticoulat Guimarães, senador em 1955; (OLIVEIRA, 2000, p.390), tendo ocupado os seguintes cargos: Prefeito de Curitiba, Vice-presidente do Conselho Administrativo do Estado do Paraná entre 1946 e 1947, secretário de Saúde e Assistência Social, no governo de Moisés Lupion (1947-1951), Secretário do Interior e Justiça em 1951 (DHBB CPDOC FGV22). Alô Guimarães era irmão de Acyr Guimarães, deputado federal pelo Paraná de 1946 a 1948 (IPARDES, 1987). Outro político influente da família é Algacyr Guimarães, presidente do Banestado e Conselheiro do Tribunal de Contas. (OLIVEIRA, 2000, p.390). Secretário da Fazenda, governo Ney Braga (1961-1965), governador interino do Paraná, 1965, Diretor-Geral do DNER (Departamento Nacional de Estradas de Rodagem), nomeado por Castello Branco, em fevereiro de 1966 (CASA CIVIL ${ }^{23}$; GRANATO, 2016). A família também conta com a influência de Arcésio Guimarães, Presidente da Associação Comercial do Paraná 1933, bisneto do Visconde de Nácar, vereador em Curitiba, presidente da Câmara Municipal, (LAIBIDA, 2016, p.98) e Noel Lobo Guimarães, Presidente da Associação Comercial do Paraná em 1966 (OLIVEIRA, 2000, p.390) e Secretário de Estado do Interior, governo Jayme Canet ${ }^{24}$

A família Guimarães, além de contar com notório capital econômico (demonstrado também com a presença de membros na Associação Comercial do Paraná), político (conforme o visto nos principais cargos ocupados por membros da família), ainda possuía capital cultural. Flávio Guimarães se formou em Direito, na Faculdade de Direito de São Paulo, no ano de 1916. Era

\footnotetext{
${ }^{21}$ ALEP. Plauto Miró Guimarães Filho. Disponível em: http://www.alep.pr.gov.br/deputados/perfil/50-plauto-miro. . Acesso 13.maio.2017.

22 DHBB CPDOC FGV. Alô Ticoulat Guimarães. Disponível em: http://www.fgv.br/cpdoc/acervo/dicionarios/verbetebiografico/guimaraes-alo-ticoulat. . Acesso 13.maio.2017.

23 CASA CIVIL Algacyr Guimarães. Disponível http://www.casacivil.pr.gov.br/modules/conteudo/conteudo.php?conteudo=75. . Acesso 13.maio.2017.
}

24 Legislação Estadual de Recursos Humanos. Disponível em: http://celepar7cta.pr.gov.br/seap/legrhv1.nsf/5199c876c8f027f603256ac5004b67da/b4707d35d504330503256aae0060ad3d?OpenDocument. . Acesso 13.maio.2017. 
latifundiário na região dos Campos Gerais. Pertenceu à Academia Paranaense de Letras e ao Centro de Letras do Paraná (DHBB CPDOC FGV ${ }^{25}$ ).

Flávio Guimarães teve destacada carreira política no período pós-1930. Exerceu o cargo de Secretário da Fazenda e Obras Públicas do Paraná em 1934 e foi membro do Conselho Administrativo. Foi escolhido senador entre os deputados federais do Paraná em 1935 (DAGOSTIM, 2011, p. 167; DHBB CPDOC FGV). Foi ainda diretor da Caixa Econômica Federal do Paraná, de 1938 a 1945, diretor-presidente Caixa Econômica Federal em 1945 (DHBB CPDOC FGV). Foi eleito senador do Paraná, pelo PSD, de 1945 a 1955.

\section{CONSIDERAÇÕES FINAIS}

Analisando a trajetória dos cinco senadores paranaenses contemporâneos da Revolução de 1930, percebemos a correspondência entre capitais políticos, econômicos, sociais e culturais, sendo os mesmos portadores de grande acúmulo de capitais que foram decisivos em suas respectivas carreiras. Todos eles pertenciam a famílias da classe dominante estabelecidas no Paraná há séculos. Um acontecimento como a Revolução de 1930 não proporcionou impacto negativo sobre as famílias políticas dominantes paranaenses, pelo menos no que se refere às famílias dos senadores analisados pelo presente trabalho.

O mesmo não acontece em relação às suas trajetórias políticas individuais. Cavalcanti de Albuquerque, por exemplo, não retomou a sua carreira política após 1930, e nem a geração de descendentes seus obteve grandes êxitos no campo de poder local. O senador Marins Alves de Camargo também não retomou sua careira política no período pós-1930, mas a geração Camargo posterior à sua alcançou grandes postos nos círculos de poder local no período pós-1945, permanecendo na ditadura militar e redemocratização. Já o terceiro senador analisado do período pré-1930, Caetano Munhoz da Rocha, afasta-se momentaneamente da política com a Revolução, mas retoma sua carreira pouco tempo depois, obtendo cargos importantes no período pós-1930, contando com boas relações junto à Getúlio Vargas e a máquina política local nas décadas de 1930 e 1940, em detrimento de suas ligações com o período anterior à Revolução, o que indica

25 DHBB $\quad$ CPDOC $\quad$ FGV. Flávio Carvalho Guimarães. Disponível em:


claramente que tal acontecimento se deu através de uma "modernização conservadora", corroborando-se também com as ideias desenvolvidas por Ricardo Costa de Oliveira (2004) no que se refere à conciliação de velhas e novas forças sociais e políticas no Paraná após 1930. A geração posterior à Caetano Munhoz da Rocha angariou importantes cargos e influência política no período pós-1945, declinando sua influência com a ditadura militar e a redemocratização.

Entre os senadores do período posterior a 1930, observa-se uma ascensão da carreira política dos mesmos com a Revolução. Antônio Machado da Silva Lima ocupou vários cargos neste período, e herdou muitos capitais da geração que antecedeu à sua. Porém, a geração posterior da família Machado da Silva Lima não obteve grandes êxitos políticos nos principais períodos da república no século XX. Em contrapartida, o senador Flávio Carvalho Guimarães angariou importantes cargos com a Revolução de 1930, incrementado os capitais que já tinha herdado de sua família. A geração posterior à sua manteve a influência e o prestígio político nos períodos posteriores, exercendo grande influência nos círculos de poderes locais contemporâneos.

\section{REFERÊNCIAS}

ALEP. Disponível em: http://www.alep.pr.gov.br/deputados

ALEP. Plauto Miró Guimarães Filho. Disponível em:

http://www.alep.pr.gov.br/deputados/perfil/50-plauto-miro

ALVES, Luiz Antônio. A grande nação: Tibiriçá. São Paulo, EST edições, 2003.

BIOGRAFIA Eunice Miró Guimarães Cordeiro. Disponível em:

http://sme.pontagrossa.pr.gov.br/anfiteatro.php

BOURDIEU, Pierre. Coisas Ditas. São Paulo: Brasiliense, 2004.

BOURDIEU, Pierre. O senso prático. Petrópolis: Vozes, 2009.

$\begin{array}{lllll}\text { CASA CIVIL. } & \text { Algacyr } & \text { Guimarães. }\end{array}$

http://www.casacivil.pr.gov.br/modules/conteudo/conteudo.php?conteudo=7

CASA CIVIL. Caetano Munhoz da Rocha. Disponível em:

http://www.casacivil.pr.gov.br/modules/conteudo/conteudo.php?conteudo=60

CASA CIVIL. Carlos Cavalcanti de Albuquerque. Disponível em:

http://www.casacivil.pr.gov.br/modules/conteudo/conteudo.php?conteudo=46 
CASA

Marins

Alves

de

Camargo.

Disponível

em:

http://www.casacivil.pr.gov.br/modules/conteudo/conteudo.php?conteudo=104

CASA CIVIL. Vicente Machado da Silva Lima. Disponível em:

http://www.casacivil.pr.gov.br/modules/conteudo/conteudo.php?conteudo=36

CORRÊIA, Amélia Siegel. Imprensa e Política no Paraná: uma prosopografia dos redatores republicanos. Clio- Revista de Pesquisa Histórica, n. 24, 2006

DAGOSTIM, Maristela Wessler. A república dos Conselhos: um estudo sobre a transformação do perfil da elite paranaense (1930-1947). Dissertação. Mestrado em Ciência Política. Curitiba: Universidade Federal do Paraná, 2011.

DHBB CPDOC FGV. Alô Ticoulat Guimarães. Disponível em:

http://www.fgv.br/cpdoc/acervo/dicionarios/verbete-biografico/guimaraes-alo-ticoulat

DHBB CPDOC FGV. Carlos Cavalcanti de Albuquerque. Disponível em:

http://cpdoc.fgv.br/sites/default/files/verbetes/primeira-

republica/ALBUQUERQUE,\%20Carlos\%20Cavalcanti\%20de.pdf

DHBB CPDOC FGV. Flávio Carvalho Guimarães. Disponível em:

http://www.fgv.br/cpdoc/acervo/dicionarios/verbete-biografico/flavio-carvalho-guimaraes

DHBB CPDOC FGV. Marins Camargo. Disponível em:

http://cpdoc.fgv.br/sites/default/files/verbetes/primeira-

republica/CAMARGO,\%20Marins.pdf

DHBB CPDOC FGV. Verbete ALMEIDA BARRETO. Disponível em:

http://cpdoc.fgv.br/sites/default/files/verbetes/primeira-

republica/BARRETO,\%20Almeida.pdf

DHBB CPDOC FGV. Verbete Antônio Jorge Machado Lima. Disponível em: http://www.fgv.br/cpdoc/acervo/dicionarios/verbete-biografico/lima-antonio-jorge$\underline{\text { machado }}$

DHBB CPDOC FGV. Verbete Caetano Munhoz da Rocha. Disponível em: http://cpdoc.fgv.br/sites/default/files/verbetes/primeirarepublica/ROCHA,\%20Caetano\%20Munhoz\%20da.pdf

DICIONÁRIO HISTÓRICO E GEOGRÁFICO DOS CAMPOS GERAIS. Disponível em: http://www.uepg.br/dicion/verbetes/a-m/guimaraes jose.htm 
FAUSTO, Boris. A Revolução de 1930: Historiografia e História. São Paulo: Companhia das Letras, 1997.

GOULART, Mônica Helena Harrich Silva. Classe dominante e jogo político na Assembleia Legislativa paranaense (1889-1930). Tese. Doutorado em Sociologia. Curitiba: Universidade Federal do Paraná, 2008.

GOULART, Mônica Helena Harrich Silva. Família Slaviero: uma história de grandes conquistas. Revista NEP (Núcleo de Estudos Paranaenses) Curitiba, v.2, n.2, p.720-734, maio 2016.

GRANATO, Natália Cristina. O campo político paranaense no contexto do golpe de 1964 e suas lutas políticas. Dissertação. Mestrado em Sociologia. Curitiba: Universidade Federal do Paraná, 2016.

IPARDES. Resultados Eleitorais no Paraná: 1945-1982. Curitiba: IPARDES, 1987

LAIBIDA, Luiz Demétrio Janz. Raposas e outsiders no futebol paranaense: um estudo sobre relações de poder e genealogia. Tese. Doutorado em Sociologia. Universidade Federal do Paraná, 2016.

LEGISLAÇÃO Estadual de Recursos Humanos. Disponível em:

http://celepar7cta.pr.gov.br/seap/legrh-

v1.nsf/5199c876c8f027f603256ac5004b67da/b4707d35d504330503256aae0060ad3d?Open

Document

MARTINS, Luciano. A Revolução de 1930 em Perspectiva: Estado, Estrutura de Poder e Processo Político. In: A revolução de 30: Seminário realizado pelo Centro de Pesquisa e Documentação de História Contemporânea do Brasil (CPDOC) da Fundação Getúlio Vargas. Brasília: Editora Universidade de Brasília, 1983.

NICOLAS, Maria. O Paraná no Senado. Curitiba: Imprensa Oficial do Estado do Paraná, [S/D].

OLIVEIRA, Ricardo Costa de. Notas sobre a política paranaense no período de 1930 a 1945. In: OLIVEIRA, Ricardo Costa de (org.). A Construção do Paraná Moderno: Políticos e Política no governo do Paraná de 1930 a 1980. Curitiba: Secretaria da Ciência, Tecnologia e Ensino Superior do Paraná, 2004.

OLIVEIRA, Ricardo Costa de. O silêncio das genealogias: classe dominante e estado no Paraná (1853-1930). Tese. Doutorado em Sociologia. Universidade Estadual de Campinas, 2000.

ORTIZ, Renato. "A procura de uma sociologia da prática". In BOURDIEU, Pierre. Pierre Bourdieu: sociologia. Coleção Grandes Cientistas Sociais. São Paulo: Ática, 1983. 
PEREIRA, José Carlos. Formação industrial do Brasil e outros estudos. São Paulo: Secretaria de Estado da Cultura: Hucitec, 1984.

PREFEITOS de Ponta Grossa. Disponível em: http://www.plantaodacidade.com.br/novo/prefeitos

$\begin{array}{lllll}\text { PREFEITURA } & \text { DE } & \text { DUNHOZ }\end{array}$
http://www.munhozdemello.pr.gov.br/index.php?sessao=b054603368ncb0\&id=1267

SOARES, Gláucio Ary Dillon. Sociedade e Política no Brasil. São Paulo: Difusão Europeia do Livro,1973.

SOUZA, Maria do Carmo Campello de. Estado e Partidos Políticos no Brasil (1930 a 1964). São Paulo: Alfa-Ômega, 1976.

TJ PARANÁ. Disponível em: https://www.tjpr.jus.br/desembargadores-tjpr-museu//asset publisher/V8xr/content/des-jose-munhoz-de-mello/397262?inheritRedirect=false

TJ PARANÁ. Eudoro Cavalcanti de Albuquerque. Disponível em: https://www.tjpr.jus.br/desembargadores-tipr-museu/-/asset publisher/V8xr/content/deseudoro-cavalcanti-de-albuquerque/397262?inheritRedirect=false 